\title{
Validating Quantitative Polymerase Chain Reaction Assay for the Molecular Diagnosis of Chronic Suppurative Otitis Media
}

\author{
Dina Alia ${ }^{1,2}$, Ferry Dwi Kurniawan ${ }^{3}$, Azwar Ridwan $^{2}$, Wilda Mahdani ${ }^{4}$, Koichi Hagiwara $^{1,5 *}$ \\ ${ }^{1}$ Department of Internal Medicine, Comprehensive Medicine I, Saitama Medical Centre, Jichi Medical University, Saitama, \\ Japan; ${ }^{2}$ Department of Ear, Nose and Throat, Faculty of Medicine, dr. Zainoel Abidin Hospital, Universitas Syiah Kuala, Banda \\ Aceh, Indonesia; ${ }^{3}$ Department of Respiratory Medicine, Faculty of Medicine, Dr. Zainoel Abidin Hospital, Universitas Syiah \\ Kuala, Banda Aceh, Indonesia; ${ }^{4}$ Department of Microbiology, dr. Zainoel Abidin Hospital, Universitas Syiah Kuala, Banda Aceh, \\ Indonesia; ${ }^{5}$ Department of Internal Medicine, Division of Pulmonary Medicine, Jichi Medical University, Tochigi, Japan
}

\begin{abstract}
BACKGROUND: Pathogen identification is critical for antibiotic selection in suppurative otitis media. However, bacterial culture challenges from suppurative specimens often cause antibiotic misuse and ineffective treatment. $A$ quantitative polymerase chain reaction (PCR) controlled by the human cells contained in the specimen (HIRA-TAN) has been established in differentiate between pathogens and colonization in the previous pneumonia study.

AIM: The aim of this study was to investigate the utility of HIRA-TAN and determine the causative pathogen in chronic suppurative otitis media.

METHODS: Thirty-nine patients were recruited to the study. The otorrhea was swab-collected and processed for both bacterial culture and a multiplex PCR-based test. The cutoff of cycle threshold to determinate the pathogens was defined by receiver operating characteristic curves.

RESULTS: Thirty-nine patients ranging from 1.7 to 62 years old were enrolled. The hearing impairment was found different between adult and children $(\mathrm{p}<0.005)$ with adults $(24 / 29$ patients) had a significantly higher rate. A total of $35.9 \%$ of samples were positive for bacterial culture; Pseudomonas aeruginosa, Klebsiella pneumoniae, Proteus mirabilis, and Morganella morganii, while Bacteroides fragilis, Acinetobacter baumannii, Moraxella catarrhalis, and Escherichia coli were not identified by culture, although high cycle-threshold values were obtained suggesting the inability of the culture system in detecting some pathogens.

CONCLUSION: Our results indicate that HIRA-TAN is a potential diagnostic tool in suppurative otitis media and warrant a larger cohort study.
\end{abstract}

Edited by: Mirko Spirosk Citation: Alia D, Kurniawan FD, Ridwan A, Mahdani W, Hagiwara K. Validating Quantitative Polymerase Chain Reaction Assay for the Molecular Diagnosis of Chronic Suppurative Otitis Media. Open Access Maced J Med Sci. 2020 Jun 10; 8(A):491-497. https://doi.org/10.3889 oamjms. 2020.388 Keywords: Suppurative otitis media; Pathogen; Real-time polymerase chain reaction, Molecular diagnostic Merrespondence: Koichi Hagiwara, Comprehensive 1-847 Amanuma-cho Omiya, Jichi Medical Saitama, Japan. E-mail: hagiwark@me-com Received: 14-Oct-2019 Revised: 23-Apr-2020 Accepted: 04-May-2020 Copyright: ๑ 2020 Dina Alia, Ferry Dwi Kurniawan, Azwar Ridwan, Wilda Mahdani, Koichi Hagiwara Funding: This research did not receive any financia Competing Interests: This research was a part of in-house research expenses of the Jichi University pen Access: This is an open-access article distributed under the terms of the Creative Commons Attribution-
nCommercial 4.0 International License (CC BY-NC 4.0)

\section{Introduction}

Chronic suppurative otitis media (CSOM) is a persistent infection of the middle ear associated with a perforated tympanic membrane resulting in ear discharge for more than 6 weeks [1]. The morbidity in children is high in many countries including Indonesia. Affected children often lose hearing capability [2], resulting in poor academic performances [1]. Early diagnosis, eradication of infection, and prevention of recurrence are warranted for effective control. Identification of the causative pathogens is essential for treatment strategies. However, it is challenging due to the contamination of bacteria colonizing in the ear and difficulty of culturing bacteria from suppurative specimens. Overprescription of antibiotics and over-the-counter access to antibiotics challenge health-care management [3], [4], [5].

An additional technique that can exclude the colonizing pathogens is required to define the causative pathogens. Human cell-controlled identification of the respiratory agent (HIRA-TAN method) is a technique that utilizes the battlefield hypothesis [6] for accurate pathogen identification. According to the battlefield hypothesis, the ratio of causative pathogen cells to human cells in a purulent sample is considered as an indicator for the discrimination of the causative pathogen from the colonizing organisms. A pathogen with a high ratio indicates a higher number of pathogen cells to inflammatory cells, which suggests that it is likely to be the causative pathogen. HIRA-TAN has been successfully used to differentiate the causative pathogen from commensal organisms in the untreated community-acquired pneumonia (CAP) and progressive course pneumonia [7], [8].

CSOM is a chronic inflammation where the number of pathogen cells and human inflammatory cells is in a balance - neither the pathogen overwhelms the inflammatory cells, nor the inflammatory cells dominate the pathogens. Therefore, the ratio of pathogen cells to human cells would be in a specific range, and the HIRA-TAN approach might be applicable for CSOM diagnosis. However, the technique should be validated before adopting it to the clinic. In the current study, 
we examined the utility of the HIRA-TAN method for pathogen identification that causes CSOM.

\section{Materials and Methods}

\section{Ethics approval and consent to participate}

The study was approved by both institutional review boards of Dr. Zainoel Abidin Hospital and Universitas Syiah Kuala (approval number: 06/KE/ FK/2016), and Jichi Medical University (approval number: 17-123). The signed informed consent was obtained from the study participants. The parents or guardian provided the informed consent on behalf of the children $<16$ years old.

\section{Specimen collection}

The samples were collected at the Dr. Zainoel Abidin Hospital between December 2016 and January 2017. The study recruited patients who had persistent and recurrent mucopurulent otorrhea for more than 2 months with a perforated tympanic membrane(s). Audiometry was performed to confirm hearing impairment. The external auditory canal was cleaned from the dry crust or discharge on the concha to remove the contaminant. The sterile swab stick was gently introduced into the external auditory meatus, collected the otorrhea in front of the perforated tympanic membrane. The specimen was put in the Stuart transport medium and transported to the laboratory within $2 \mathrm{~h}$. The microscopic, direct gram smear was performed directly after the sample manage from outpatient clinic to review the quality of the specimen and cell enumeration. The specimen was cultured in blood agar, MacConkey, chocolate routine media in the incubator for $24 \mathrm{~h}$. The colony morphology was identified proceed to biochemical identification test using pure culture.

\section{Multiplex TaqMan assay \\ DNA extraction}

DNA was extracted using the Blood/Cell DNA Mini Kit GB100 (Geneaid, Taipei, Taiwan), following the manufacturer's instructions. Briefly, the sample was suspended in $150 \mu \mathrm{l}$, GT Buffer. After adding $200 \mu \mathrm{l} \mathrm{GB}$ Buffer, the sample was vigorously shaken in a $1.5 \mathrm{ml}$ centrifuge tube. The mixture was incubated at $60^{\circ} \mathrm{C}$ for more than $15 \mathrm{~min}$, and DNA was eluted in $100 \mu \mathrm{l}$ double distilled water.

\section{Real-time polymerase chain reaction (PCR)}

The reaction for 16 different targets was performed in four separated tubes. Each tube contained
Table 1: Clinical characteristics

\begin{tabular}{lll}
\hline Signs and symptoms & Children $(\%)$ & Adult (\%) \\
\hline Ear discharge & $10(100)$ & $29(100)$ \\
Ear pain & $4(40)$ & $20(68.9)$ \\
Itching & $7(70)$ & $18(62)$ \\
Fever & $3(30)$ & $10(34.4)$ \\
Hearing impairment & $3(30)$ & $24(82.7)$ \\
\hline${ }^{*}$ Fisher's exact test, $\mathrm{p}<0.005$. & &
\end{tabular}

$25 \mu \mathrm{L}$ reaction mixture consisting of $12.5 \mu \mathrm{l}$ Takara Premix Ex Taq (Takara Bio Inc., Shiga, Japan), primers for pathogens or human tumor necrosis factor (TNF) gene (250 nM each), fluorescence-labeled detection probes for pathogens or the human TNF gene (250 nM each), and DNA (20 ng per tube). The real-time PCR reaction was performed using a SmartCycler II (Cepheid Inc., Sunnyvale, USA) with continuous monitoring of fluorescence. The cycling condition included an initial denaturation at $95^{\circ} \mathrm{C}$ for $30 \mathrm{~s}$, followed by 35 cycles of $95^{\circ} \mathrm{C}$ for $8 \mathrm{~s}, 61^{\circ} \mathrm{C}$ for $25 \mathrm{~s}$, and $72^{\circ} \mathrm{C}$ for $20 \mathrm{~s}$. The realtime PCR setting (Supplementary Table 1) was similar performed from the previous study [8].

\section{Primers and probes design}

Primers and fluorescent probes (Supplementary Table 2) were designed for common pathogens reported such as Pseudomonas aeruginosa, Staphylococcus aureus, Streptococcus pneumoniae, Haemophilus influenzae, Moraxella catarrhalis, Escherichia coli, Klebsiella spp., Bacteroides spp., and Proteus spp. [9], [10] based on the genome sequences obtained from the National Centre for Biotechnology Information (NCBI) nucleotide database. A pair of primer and a fluorescent-labeled probe reflects target detection. Sixteen targets were able differentiate five genera (Pseudomonas spp., Enterobacter spp., Staphylococcus spp., Streptococcus spp., and Proteus spp.), nine species ( $P$. aeruginosa, E. coli, $S$. aureus, S. pneumoniae, K. pneumoniae, A. baumannii, $H$. influenza, M. catarrhalis, and $B$. fragilis), a methicillin resistance gene $(\operatorname{mec} A)$, and a human tumor necrosis factor gene (TNF).

\section{Statistical analysis}

The clinical informations were tabulated using the spreadsheet program. A free software based on R, EZR version 1.36, was executed for statistical analysis [11]. Fisher's exact test was used for nonrandom associations between two categorical variables. The receiver-operating characteristic (ROC) curve analysis was performed by designating the culture result compare to the delta Ct value for each sample. The outputs were the area under curve value with the $95 \%$ confidence interval, sensitivity versus (1-specificity) graph, and sensitivity/specificity graph. The ROC curve, the sensitivity and specificity value, and threshold value were analyzed and utilized as the cutoff. 


\section{Results}

\section{Clinical characteristics}

Thirty-nine patients (mean age $=32$ years) (1.7-62) were enrolled in the study. Twenty-nine were adults (>20-year-old), and ten were children. The symptoms reported were ear discharge (100\%), hearing problems $(69.2 \%)$, ear pain $(61.5 \%)$, ear itching (64.1\%), and fever (33.3\%). Adults (24/29 patients) had a significantly higher rate of hearing impairment than children (3/10 patients; Table 1).

\section{HIRA-TAN}

For determining whether HIRA-TAN can be used to identify the causative pathogen, we performed a real-time PCR analysis for all 16 targets (15 targets were for pathogen genes and one for the human gene) and plotted the $\Delta C t_{\text {Pathogen }}$ values (Figure 1). The samples were also subjected to bacterial culture, and positive results were obtained in 14 patients $(36 \%)$. Cultured bacteria included $P$. aeruginosa, K. pneumoniae, Proteus mirabilis, and Morganella morganii (Black dots in Figure 1; Supplementary Table 3). The samples positive for culture (black dots) showed a high $\Delta C t_{\text {pathogen }}$. However, some samples negative for culture (white dots) showed similar $\Delta C t_{\text {Pathogen }}$ values. These samples were considered as false negative culture results or samples in which most of the bacteria are not alive.

The $\Delta C t_{\text {Pathogen }}$ of bacterial detection by the HIRA-TAN method. The red line indicates the cutoffs. (a) P. aeruginosa, (b) K. pneumoniae, (c) Proteus sp., (d) B. fragilis, (e) A. baumannii, (f) M. catarrhalis, and (g) E. coli. Bacteria a-c were isolated from bacterial cultures, and the cutoff values were calculated using ROC analysis, while $\mathrm{d}-\mathrm{g}$ were not isolated, and the ROC cutoff values were not calculated. Ct above 30 was eliminated.

We performed the ROC curve analysis in four pathogens that were detected by culture in at least one sample for determining the $\Delta C t_{\text {Pathogen }}$ cutoff for identifying the causative pathogen (Figure 1 , red lines). The $\Delta C t_{\text {Pathogen }}$ cutoff, sensitivity, and specificity values were as follows: P. aeruginosa: 3.33 (90\%, 100\%), K. pneumoniae: 1.71 (85\%, 100\%), and Proteus sp: 8.29 $(90 \%, 100 \%)$ (Supplementary Figure 1). The $\Delta C t_{\text {Pathogen }}$ cutoff for $B$. fragilis, A. baumanii, M. catarrhalis, and $E$. coli could not be determined, as they were not detected by culture. The results indicated that HIRATAN picked up pathogens that are likely to be the causative pathogen among the culture positives.

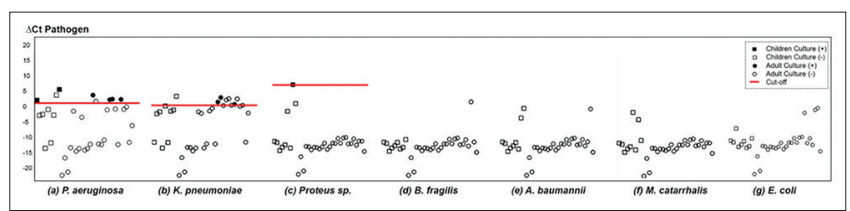

Figure 1: HIRA-TAN test results
Plot of sensitivity and specificity against $\Delta \mathrm{Ct}$ pathogen values for identifying the threshold value or cutoff value. The $\Delta \mathrm{Ct}$ pathogen cutoff values with sensitivity and specificity values of (a) $P$. aeruginosa was $3.33(90 \%, 100 \%)$, (b) K. pneumoniae was 1.71 $(85 \%, 100 \%)$, and (c) Proteus sp. was $8.29(90 \%$, $100 \%$ ). Ct above 30 was eliminated.

\section{HIRA-TAN using copy number}

Real-time PCR was able to determine the copy number of the targets in the samples semi-quantitatively. Therefore, HIRA-TAN may be performed to determine copy numbers both human and pathogen genome. Using the human genomic DNA and the genomic DNA from ten pathogens, we plotted a standard curve and performed HIRA-TAN analysis (Supplementary Figure 2). The results were not conclusive - culture-positive samples were not well discriminated from the culture-negative samples.

Copy number ratio of each pathogen to human genomic DNA, showing that some samples had 287.87 times $P$. aeruginosa, 123.79 times $K$. pneumonia, and 530.03 times Proteus sp genomic DNA. The copy number ratios of $B$. fragilis, $A$. baumannii, $M$. catarrhalis, and $E$. coli were below 10 .

\section{Discussion}

All age groups were affected suggesting that CSOM is a common disease as reported in many developing countries [9], [10]. The higher hearing impairment proportion in adult than children indicates an irreversible process. It implies that the infection may be poorly eradicated in the childhood. Repeated infection episodes and inadequate treatment in childhood were associated with acquired hearing loss [12], [13]

Pathogens that were identified by bacterial culture showed a higher $\Delta C t_{\text {Pathogen }}$ value, suggesting that HIRA-TAN may be used for causative pathogen identification. The patient age in the study population showed a broad distribution, consistent with the reports that CSOM is a disease involving all age groups [9], [10]. The rate of hearing impairment was higher in adults than in children. Repeated episodes of infection and inadequate treatment during childhood have been associated with acquired hearing loss [12], [13]. Early and complete eradication of infection is critical for managing CSOM.

Our results reported that the most frequently isolated bacteria from CSOM samples are $P$. aeruginosa, Proteus spp., and Klebsiella spp. and are in line from earlier studies [14], [15]. The difference with other reports may be due to the difference in the study population or geography [16]. Our results are 
consistent with a previous study that reported only a limited number of bacterial species cause CSOM. Accordingly, many hospital laboratories screen only a small number of species during routine tests [17]. Considering the number of the candidate species and consistency of our results with the previous reports, HIRA-TAN may be an attractive approach for identifying the causative pathogen of CSOM.

B. fragilis, A. baumannii, M. catarrhalis, and $E$. coli showed high $\Delta C t_{\text {Pathogen }}$ values. Nevertheless, they were not detected by bacterial culture and the ROC curve analysis could not be performed. The results of PCR indicate that numerous bacteria are present in the specimen. It may be possible that many bacteria were nonviable. It is known that DNA from nonviable bacteria do not persist for more than 1 day in middle ear effusions [18]. Furthermore, the culture-sterile middle ear effusion has been suggested to be viable and metabolically active [19]. Therefore, a positive HIRATAN result likely indicates viable but not culturable bacteria in the sample, which may be included as therapeutic targets.

The undetected Gram positive in this study can be due to several factors. The ear canal cleansing prior swab collection decreased contamination. Prior oral antibiotic received from Primary Health Care due to recurrence otorrhea can inhibit the Grampositive bacteria. Consider the following factors such as inappropriate prescription practices, inadequate patient education, unauthorized sale of antibiotics, and limited diagnostic facilities are occurred in Indonesia [20].

The battlefield hypothesis has been applied to pneumonia, which is an acute infection. Our result suggests that it may also be applied to a chronic infection, and the number of human inflammatory cells and pathogen cells may be in a balance. For improving pathogen identification in CSOM, HIRA-TAN method may be alternative in addition to culture. Larger cohort study is required to be implemented and the current study is a reasonable beginning. Studies using other chronic infections such as chronic rhinosinusitis will be interesting and provide more information.

\section{Conclusion}

HIRA-TAN test results were consistent with the bacterial culture results and suggested a list of pathogens that may be considered as therapeutic targets. A high $\Delta C t_{\text {Pathogen }}$ in culture-negative samples may indicate viable but non-culturable bacteria. These bacteria are ignored when determining the therapeutic regimen, but their pathogenic role requires reconsideration. Our results warrant larger cohort study that investigates the utility of HIRA-TAN for CSOM.

\section{Acknowledgments}

We thank Megumi Higo, Akemi Okumura, and Yuka Yoshino for assisting the administration. We thank Jichi Medical University for provide research fund which had no role in study design, data collection and analysis, and manuscript preparation. We also appreciate the support from Universitas Syiah Kuala and dr. Zainoel Abidin Hospital staffs.

\section{References}

1. Daud MK, Noor RM, Rahman NA, Sidek DS, Mohamad A. The effect of mild hearing loss on academic performance in primary school children. Int J Pediatr Otorhinolaryngol. 2010;74(1):6770. https://doi.org/10.1016/j.ijporl.2009.10.013 PMid:19913305

2. Anggraeni R, Hartanto WW, Djelantik B, Ghanie A, Utama DS, Setiawan EP, et al. Otitis media in Indonesian urban and rural school children. Pediatr Infect Dis J. 2014;33(10):1010-5. https://doi.org/10.1097/inf.0000000000000366

PMid:24830700

3. Mittal R, Lisi CV, Gerring R, Mittal J, Mathee K, Narasimhan G, et al. Current concepts in the pathogenesis and treatment of chronic suppurative otitis media. J Med Microbiol. 2015;64(10):1103-16. https://doi.org/10.1099/jmm.0.000155 PMid:26248613

4. Qureishi A, Lee Y, Belfield K, Birchall JP, Daniel M. Update on otitis media-prevention and treatment. Infect Drug Resist. 2014;7:15-24. https://doi.org/10.2147/idr.s39637 PMid:24453496

5. Argaw-Denboba A, Abejew AA, Mekonnen AG. Antibioticresistant bacteria are major threats of otitis media in wollo area, northeastern ethiopia: A ten-year retrospective analysis. Int J Microbiol. 2016;2016:8724671. https://doi. org/10.1155/2016/8724671

PMid:26904125

6. Hirama T, Yamaguchi T, Miyazawa H, Tanaka T, Hashikita G, Kishi E, et al. Prediction of the pathogens that are the cause of pneumonia by the battlefield hypothesis. PLoS One. 2011;6(9):e24474. https://doi.org/10.1371/journal. pone.0024474

PMid:21909436

7. Hirama T, Minezaki S, Yamaguchi T, Kishi E, Kodama K, Egashira $\mathrm{H}$, et al. HIRA-TAN: A real-time PCR-based system for the rapid identification of causative agents in pneumonia. Respir Med. 2014;108(2):395-404. https://doi.org/10.1016/j. rmed.2013.11.018

PMid:24411834

8. Kurniawan FD, Alia D, Priyanto H, Mahdani W, Hagiwara K. HIRATAN detects pathogens of pneumonia with a progressive course despite antibiotic treatment. Respir Investig. 2019;57(4):337-44. https://doi.org/10.1016/j.resinv.2019.03.001

PMid:31031122

9. DeAntonio R, Yarzabal JP, Cruz JP, Schmidt JE, Kleijnen J. Epidemiology of otitis media in children from developing countries: A systematic review. Int J Pediatr Otorhinolaryngol. 2016;85:65-74. https://doi.org/10.1016/j.ijporl.2016.03.032 PMid:27240499 
10. Mahadevan M, Navarro-Locsin G, Tan HK, Yamanaka N, Sonsuwan N, Wang PC, et al. A review of the burden of disease due to otitis media in the Asia-Pacific. Int $\mathrm{J}$ Pediatr Otorhinolaryngol. 2012;76(5):623-35. https://doi.org/10.1016/j. ijporl.2012.02.031 PMid:22404948

11. Kanda Y. Investigation of the freely available easy-to-use software 'EZR' for medical statistics. Bone Marrow Transplant. 2013;48(3):452-8. https://doi.org/10.1038/bmt.2012.244 PMid:23208313

12. Yiengprugsawan $V$, Hogan $A$, Strazdins L. Longitudinal analysis of ear infection and hearing impairment: Findings from 6-year prospective cohorts of Australian children. BMC Pediatr. 2013;13(13):28. https://doi.org/10.1186/1471-2431-13-28 PMid:23432915

13. Aarhus L, Tambs K, Kvestad E, Engdahl B. Childhood otitis media: A cohort study with 30-year follow-up of hearing (the HUNT study). Ear Hear. 2015;36(3):302-8. https://doi. org/10.1097/aud.0000000000000118

PMid:25401378

14. Yeo SG, Park DC, Hong SM, Cha Cl, Kim MG. Bacteriology of chronic suppurative otitis media-a multicenter study. Acta Otolaryngol. 2007;127(10):1062-7. https://doi. org/10.1080/00016480601126978

PMid: 17851935

15. Lee SK, Lee MS, Jung SY, Byun JY, Park MS, Yeo SG. Antimicrobial resistance of Pseudomonas aeruginosa from otorrhea of chronic suppurative otitis media patients. Otolaryngol Head Neck Surg. 2010;143(4):500-5. https://doi.org/10.1016/j.

\section{otohns.2010.06.906}

PMid:20869558

16. Prakash R, Juyal D, Negi V, Pal S, Adekhandi S, Sharma M, et al. Microbiology of chronic suppurative otitis media in a tertiary care setup of Uttarakhand state, India. N Am J Med Sci. 2013;5(4):282-7. https://doi.org/10.4103/1947-2714.110436 PMid:23724403

17. Neeff M, Biswas K, Hoggard M, Taylor MW, Douglas R. Molecular microbiological profile of chronic suppurative otitis media. J Clin Microbiol. 2016;54(10):2538-46. https://doi. org/10.1128/jcm.01068-16

PMid:27487953

18. Post JC, Aul JJ, White GJ, Wadowsky RM, Zavoral T, Tabari R, et al. PCR-based detection of bacterial DNA after antimicrobial treatment is indicative of persistent, viable bacteria in the chinchilla model of otitis media. Am J Otolaryngol. 1996;17(2):106-11. https://doi.org/10.1016/s0196-0709(96)90005-8 PMid:8820185

19. Rayner MG, Zhang Y, Gorry MC, Chen Y, Post JC, Ehrlich GD. Evidence of bacterial metabolic activity in culture-negative otitis media with effusion. JAMA. 1998;279(4):296-9. https://doi. org/10.1001/jama.279.4.296

PMid:9450714

20. Widayati A, Suryawati S, de Crespigny C, Hiller JE. Self medication with antibiotics in Yogyakarta city Indonesia: A cross sectional population-based survey. BMC Res Notes. 2011;4(1):491. https://doi.org/10.1186/1756-0500-4-491 PMid:22078122 


\section{Supplementary Tables}

\section{Supplementary Table 1: Multiplex PCR reactions}

\begin{tabular}{lllll}
\hline Reaction & FAM & Cy3 & Texas Red & Cy5 \\
\hline I & Homo sapiens (TNF) & Pseudomonas sp. (16S rRNA) & Enterobacter sp. (tusB) & Staphylococcus sp. (Tuf) \\
II & P. aeruginosa (23S rRNA) & K. pneumonia (gapA) & S. pneumonia (Pneumolysin) & S. aureus (Thermonuclease) \\
III & A. baumannii (ompA) & E. coli (phoA) & Streptococcus sp. (Tuf) & H. influenza (16S rRNA) \\
IV & M. catarrhalis (CopB) & B. fragilis (16S rRNA) & Proteus sp. (16S rRNA) & Methicillin-resistant S. aureus; MRSA (mecA) \\
\hline PCR was performed in four separate multiplex reactions. The SmartCycler II (Cepheid Inc., Sunnyvale, USA) is able to simultaneously detect four fluorescent channels. We used four fluorophores - FAM for the FAM \\
channel, ALEXA532 for the Cy3 channel, ALEXA594 for the Texas Red channel, and ALEXA647 for the Cy5 channel. Temperature and time parameters were $30 \mathrm{~s}$ of an initial denaturation prior 30 cycles of 95 $95^{\circ} \mathrm{C}$ for $8 \mathrm{~s}$, \\
$61^{\circ} \mathrm{C}$ for 25 s, and $72^{\circ} \mathrm{C}$ for $20 \mathrm{~s}$ s.
\end{tabular}

Supplementary Table 2: Primer and probes of the target genes

\begin{tabular}{|c|c|c|c|c|c|}
\hline No & Target & Gene (Accession number) & & Oligonucleotide & Amplicon (bp) \\
\hline \multirow[t]{3}{*}{1} & Homo sapiens & TNF (NC_000006.12) & $\mathrm{F}^{*}$ & 5'-GTGGAGCTGAGAGATAACCAGC-3' & 153 \\
\hline & & & B & 5'-GACCTTGGTCTGGTAGGAGACG-3' & \\
\hline & & & $\mathrm{P}$ & FAM-CTGTACCTCATCTACTCCCAGGTC-BHQ1 & \\
\hline \multirow[t]{3}{*}{2} & Pseudomonas sp. & 16S rRNA (AY486350.1) & $\mathrm{F}$ & 5'-GTGAGTAATGCCTAGGAATCTGC-3' & 135 \\
\hline & & & B & 5'-CTAATCCGACCTAGGCTCATCTG-3' & \\
\hline & & & $\mathrm{P}$ & ALEXA532-AGTGGGGGATCTTCGGACCTC-BHQ1 & \\
\hline \multirow[t]{3}{*}{3} & Enterobacter $s p$. & tusB (AH002539.2) & $\mathrm{F}$ & 5'-CGTCAGACTTACGGTTAAGCAC-3' & 193 \\
\hline & & & B & 5'-GTACCAGCTGGTTAACTGTTGC-3' & \\
\hline & & & $\mathrm{P}$ & ALEXA594-AGCCAGATGGCCTGGTGATG-BHQ2 & \\
\hline \multirow[t]{3}{*}{4} & Staphylococcus $s p$. & Tuf (NC_007168.1) & $\mathrm{F}$ & 5'-CTCAATCACTGGTCGTGGTACTG-3' & 163 \\
\hline & & & B & 5'-GTCACCAGCTTCAGCGTAGTC-3' & \\
\hline & & & $\mathrm{P}$ & ALEXA647-CGTGTTGAACGTGGTCAAATCA-BHQ2 & \\
\hline \multirow{3}{*}{5} & Pseudomonas aeruginosa & 23S rRNA (AJ549386.1) & $\mathrm{F}$ & 5'-GTTGTCCAAGTTTAAGGTGGTAGG-3' & 97 \\
\hline & & & B & 5'-CCACTTCGTCATCTAAAAGACGAC-3' & \\
\hline & & & $\mathrm{P}$ & FAM-TTCAAGGCCGAGAGCTGATGAC-BHQ1 & \\
\hline \multirow[t]{3}{*}{6} & Klebsiella pneumoniae & gapA (M66869.1) & $\mathrm{F}$ & 5'-CATCGAGATCGTTGCAATCAACG-3' & 81 \\
\hline & & & B & 5'-CGACCGTGAGTGGAGTCATAC-3' & \\
\hline & & & $\mathrm{P}$ & ALEXA532-AGACGCAGAGTACATGGCTTACATG-BHQ1 & \\
\hline \multirow[t]{3}{*}{7} & Streptococcus pneumoniae & Pneumolysin (NC_003098.1) & $\mathrm{F}$ & 5'-CAAGGTAAGGAAGTCTTGACTCC-3' & 193 \\
\hline & & & B & 5'-GCTTACGCACTAGTGGCAAATCGG-3' & \\
\hline & & & $\mathrm{P}$ & ALEXA594-AGGGAATGTTCGTAATCTCTCTGTC-BHQ2 & \\
\hline \multirow[t]{3}{*}{8} & Staphylococcus aureus & Thermonuclease (NC_007795) & $\mathrm{F}$ & 5'-GTCCTGAAGCAAGTGCATTTACG-3' & 282 \\
\hline & & & B & 5'-GACCTGAATCAGCGTTGTCTTC-3' & \\
\hline & & & $\mathrm{P}$ & ALEXA647-CGAAGCTTTAGTTCGTCAAGGCTTG-BHQ2 & \\
\hline \multirow[t]{3}{*}{9} & Acinetobacter baumannii & ompA (AY485227.1) & $\mathrm{F}$ & 5'-GAACTATACAGCTCTTGCTGGC-3' & 87 \\
\hline & & & B & 5'-CTCTTGTGGTTGTGGAGCAAC-3' & \\
\hline & & & $\mathrm{P}$ & FAM-GTTCTTGGTGGTCACTTGAAGC-BHQ1 & \\
\hline \multirow[t]{3}{*}{10} & E. coli & phoA (M29670.1) & $\mathrm{F}$ & 5'-CGAAGAGGATTCACAAGAACATACC-3' & 88 \\
\hline & & & B & 5'-CATTAAGTCTGGTTGCTAACAGC-3' & \\
\hline & & & $\mathrm{P}$ & ALEXA532-TCAGTTGCGTATTGCGGCGTATG-BHQ1 & \\
\hline \multirow[t]{3}{*}{11} & Streptococcus sp. & Tuf (AY267003.1) & $\mathrm{F}$ & 5'-CACTGGACGTGGTACAGTTGCTTC-3' & 188 \\
\hline & & & B & 5'-GAACACCACGAAGAAGGACACCTAC-3' & \\
\hline & & & $\mathrm{P}$ & ALEXA594-CAACTTGACGAAGGTCTTGCTGG-BHQ2 & \\
\hline \multirow[t]{3}{*}{12} & Haemophilus influenzae & 16S rRNA (Z22806.1) & $\mathrm{F}$ & 5'-GACATCCTAAGAAGAGCTCAGAG-3' & 266 \\
\hline & & & B & 5'-CTTCCCTCTGTATACGCCATTG-3' & \\
\hline & & & $\mathrm{P}$ & ALEXA647-CCTTCGGGAACTTAGAGACAG-BHQ2 & \\
\hline \multirow[t]{3}{*}{13} & Moraxella catarrhalis & CopB (U69982.1) & $\mathrm{F}$ & 5'-GTGCGTGTTGACCGTTTTGAC-3' & 134 \\
\hline & & & B & 5'-GTGGCATAGATTAGGTTACCGCTG-3' & \\
\hline & & & $\mathrm{P}$ & FAM-CCGACATCAACCCAAGCTTTG-BHQ1 & \\
\hline \multirow[t]{3}{*}{14} & Bacteroides fragilis & 16S rRNA (AP006841.1) & $\mathrm{F}$ & 5'-GACTGCAACTGACACTGATGCTC-3' & 316 \\
\hline & & & B & 5'-CAACCATGCAGCACCTTCACAG-3' & \\
\hline & & & $\mathrm{P}$ & ALEXA532-AGATACCCTGGTAGTCCACACAG-BHQ1 & \\
\hline \multirow[t]{3}{*}{15} & Proteus sp. & 16S rRNA (NC_010554.1) & $\mathrm{F}$ & 5'-CTCTTCGGACCTTGCACTATC-3' & 127 \\
\hline & & & B & 5'-CGTGTCTCAGTCCCAGTGTG-3' & \\
\hline & & & $\mathrm{P}$ & ALEXA594-CGACGATCTCTAGCTGGTCTG-BHQ2 & \\
\hline \multirow[t]{3}{*}{16} & Staphylococcus aureus (MRSA) & $\operatorname{mec} A(A Y 786579.1)$ & $\mathrm{F}$ & 5'-CGGTAACATTGATCGCAACGTTC-3' & 108 \\
\hline & & & B & 5'-CTTTGGTCTTTCTGCATTCCTGG-3' & \\
\hline & & & $\mathrm{P}$ & ALEXA647-TGGAAGTTAGATTGGGATCATAGCG-BHQ2 & \\
\hline
\end{tabular}

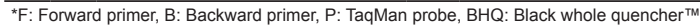

Supplementary Table 3: Culture result

\begin{tabular}{llll}
\hline Sample & Culture & Sample & Culture \\
\hline 1 & No growth & 21 & Morganella morganii \\
2 & Normal flora & 22 & Klebsiella pneumoniae \\
3 & No growth & 23 & Klebsiella pneumoniae \\
4 & No growth & 24 & No growth \\
5 & Normal flora & 25 & No growth \\
6 & No growth & 26 & Pseudomonas aeruginosa \\
7 & No growth & 27 & Pseudomonas aeruginosa \\
8 & No growth & 28 & No growth \\
9 & No growth & 29 & Klebsiella pneumoniae \\
10 & No growth & 30 & Pseudomonas aeruginosa \\
11 & Pseudomonas aeruginosa & 31 & No growth \\
12 & No growth & 32 & No growth \\
13 & No growth & 33 & No growth \\
14 & No growth & 34 & Klebsiella pneumoniae \\
15 & Pseudomonas aeruginosa & 35 & P. mirabilis \\
16 & No growth & 36 & P. mirabilis \\
17 & Normal flora & 37 & No growth \\
18 & No growth & 38 & Pseudomonas aeruginosa \\
19 & No growth & 39 & No growth \\
20 & Klebsiella pneumoniae & \multicolumn{3}{l}{} \\
\hline The specimen was put in the Stuart transport medium and immediately transported to the laboratory. The \\
specimen was cultured in blood agar, MacConkey, chocolate routine media in the incubator for 24 h. The \\
colony morphology was identified proceed to biochemical identification test using pure culture.
\end{tabular}




\section{Supplementary Figures}

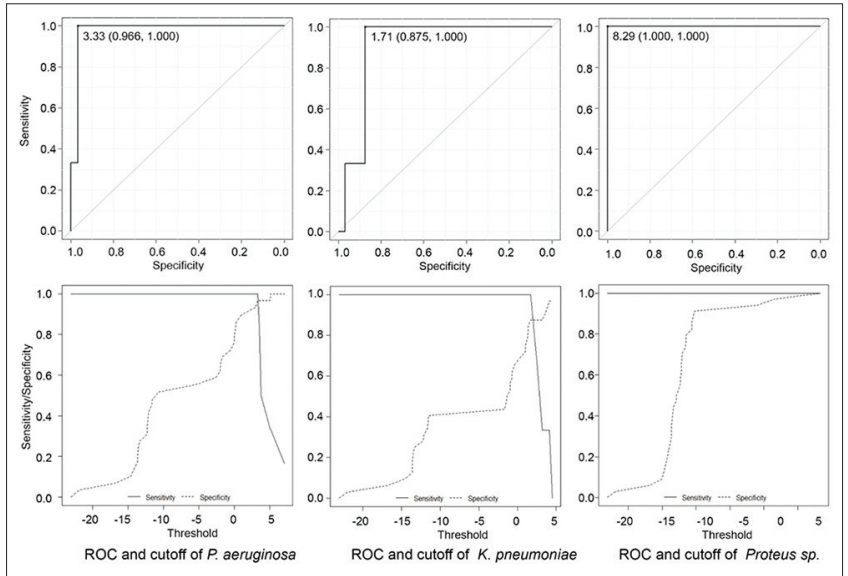

Supplementary Figure 1: The $\triangle \mathrm{Ct}$ pathogen cut- offs generated from ROC curve analysis

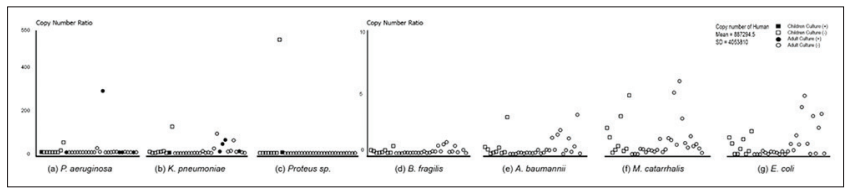

Supplementary Figure 2: Copy number ratio of pathogens to human 